\title{
Target-based drug discovery for human African trypanosomiasis: selection of molecular target and chemical matter
}

\author{
IAN H. GILBERT* \\ Division of Biological Chemistry and Drug Discovery, College of Life Sciences, University of Dundee, Dundee DD1 5EH, UK
}

(Received 19 February 2013; revised 1 Fune 2013; accepted 1 Fune 2013; first published online 9 August 2013)

SUMMARY

Target-based approaches for human African trypanosomiasis (HAT) and related parasites can be a valuable route for drug discovery for these diseases. However, care needs to be taken in selection of both the actual drug target and the chemical matter that is developed. In this article, potential criteria to aid target selection are described. Then the physiochemical properties of typical oral drugs are discussed and compared to those of known anti-parasitics.

Key words: Human African trypanosomiasis, drug discovery, target selection, target product profile.

\section{INTRODUCTION}

Human African trypanosomiasis (HAT) is endemic in sub-Saharan Africa, where millions are at risk from this disease. The disease, caused by the protozoan parasites Trypanosoma brucei gambiense and Trypanosoma brucei rhodesiense, has two stages; stage 1 is the peripheral infection, which has non-specific symptoms and stage 2 occurs when the parasite enters the central nervous system (CNS). HAT is fatal unless treated. The current treatments for stage 1 infection are suramin and pentamidine. For stage 2, the therapeutic options are melarsoprol, eflornithine and the recent combination therapy NECT (nifurtimox and eflornithine) (Brun et al. 2011). The current drugs available for treating HAT are inadequate, due to toxicity and poor efficacy. There are also problems with treatment failures for melarsoprol, although it is not known if this is due to resistance (Wilkinson and Kelly, 2009). In addition, the current treatments are inappropriate for a rural setting with poor facilities as they all require parenteral administration. There is need for new treatments for HAT, for the reasons given above, but also with the aim of elimination and eradication of this disease.

Recently there has been a marked decrease in numbers of cases and the agenda has turned more to elimination and eradication. Currently there are about 10000 recorded cases per year. However, the true number of people afflicted by this disease is estimated to be much higher due to under-reporting; probably 30000 cases per year (Brun et al. 2011). Furthermore, it is appropriate to take warnings from history, where there has been a huge change in the

* Corresponding author: Drug Discovery Unit, College of Life Sciences, University of Dundee, Dundee, DD1 5EH, UK. Tel: +44 1382 386240. Fax: +44 1382 386373. E-mail: i.h.gilbert@dundee.ac.uk number of cases; during the middle of the last century the disease was nearly eliminated, but was resurgent, and, by the end of the last century, there were an estimated 450000 people affected (Barrett, 1999, 2006; Brun et al. 2011).

There have been very few drug discovery and development programmes for HAT. Recently, however, there has been an increased effort in drug discovery for HAT and other neglected tropical diseases due to the generosity of organizations such as the Wellcome Trust, the Bill and Melinda Gates Foundation and the organization Drugs for Neglected Diseases (DNDi). This has led to increased understanding of the drug discovery processes for diseases such as HAT and infrastructure put into place for drug discovery. Given this impetus, it is now important to make sure that new medicines are delivered for HAT.

Significant recent approaches include a diamidine developed by Tidwell's group, which was taken as far as phase 3 clinical trials, but unfortunately had to be withdrawn (Barrett and Croft, 2012). Two new molecules have been moved into clinical trials by DNDi. These compounds are the nitro heterocycle fexinadazole and the oxaborole SCYX-7158. This is an exciting new development.

Drug discovery for neglected tropical diseases, such as HAT, is being conducted using both targetbased and phenotypic approaches (Gilbert et al. 2011). In this article, approaches to selection of targets and molecules for target-based drug discovery are discussed. Critical to the selection of targets and molecules is the Target Product Profile.

\section{TARGET PRODUCT PROFILE}

Target product profiles (TPP) define the requirements for a drug molecule to be clinically applicable.

Parasitology (2014), 141, 28-36. C Cambridge University Press 2013. The online version of this article is published within an Open Access environment subject to the conditions of the Creative Commons Attribution-NonCommercial-ShareAlike licence < http://creativecommons.org/licenses/by-nc-sa/3.0/ > . The written permission of Cambridge University Press must be obtained for commercial re-use. 
Table 1. Example of a new stage $1+2$ target product profile (produced by DNDi)

\begin{tabular}{ll}
\hline \hline Ideal & Acceptable improvement to current stage 2 \\
\hline $\begin{array}{l}\text { Effective against stages } 1 \text { and } 2 \\
\text { Effective against infection due to } T . \text {. } \text {. gambiense } \\
\text { and } T . b \text {. rhodesiense. }\end{array}$ & $\begin{array}{l}\text { Effective against stages } 1 \text { and 2, but only used against stage } 2 . \\
\text { Effective against infection due to } T . \text {. } \text { gambiense only. }\end{array}$ \\
Clinical efficacy $>95 \%$ at 18 months follow-up & \\
Effective in melarsoprol-refractory patients & \\
$<0 \cdot 1 \%$ drug related mortality & $<1 \%$ drug related mortality \\
Safe during pregnancy, for breastfeeding women & \\
and children. & \\
Adult and paediatric formulations & \\
No monitoring for adverse events required. & Weekly simple lab testing (field testing) \\
$<7$ days p.o. q.d. & 10 days p.o. upto tid. \\
$<7$ days i.m. q.d. & 10 days i.m. q.d. \\
Stability in zone 4 for $>3$ years & Stability in zone 4 for $>12$ months \\
Cidal & Unique target (but not through uptake via \\
Multitarget & P2-transporter only). \\
$<30 € /$ course (drug cost) & $<100 € /$ course \\
& $<220 € /$ course OK if very good on other criteria. \\
\hline \hline
\end{tabular}

http://www.dndi.org/diseases-projects/diseases/hat/target-product-profile.html

These include features such as the acceptable route for dosing the compound, the duration of treatment, the patient population, cost and acceptable range of toxicity. These are defined by clinicians and public health agencies who understand the clinical needs of the patients (Wyatt et al. 2011). An example of a TPP for HAT, defined by DNDi is shown in Table 1. The TPP needs to be regularly reviewed, as it may well change due to other treatment options becoming available, changes in the clinical situation or drug resistance to existing compounds becoming a significant issue.

The target product profile will inform drug discovery projects from the very start. This helps to define both the molecular target and chemical matter that is developed during a drug discovery programme.

Thus, the molecular target must be able to fulfil the TPP. For example, in the case of HAT, the molecular target must: (1) be essential for viability of the parasite in the human host; (2) have a rapid cidal effect when inhibited and (3) be amenable to inhibition by small drug-like molecules that have the correct physiochemical properties to be orally bioavailable and cross the blood-brain barrier.

Similarly, the molecules that are for screening must be capable of fulfilling the TPP once optimized through the hits to lead and lead optimization phase. In the case of HAT for example, there is a need for orally bioavailable compounds; thus compounds that are selected should have the appropriate physicochemical and pharmacokinetic properties for oral bioavailability.

Therefore in target-based drug discovery, in order to fulfil the TPP, both the molecular target and the chemical matter must be carefully selected, and their selection actually go hand-in-hand.
SELECTION OF DRUG TARGETS

The selection of a target for drug discovery is of key importance. A target is considered truly validated when it is in the clinic for treating human diseases. In the case of HAT (and the other kinetoplastid diseases), there is really only one target fully validated to this extent, ornithine decarboxylase. This is the target of the drug eflornithine (DFMO), which is used for the treatment of HAT. There are other drug targets which have significant levels of validation though; for example, protein farnesyltransferase (Eastman et al. 2006; Gillespie et al. 2007) and S-adenosylmethionine decarboxylase (Jacobs et al. 2011; Velez et al. 2013). Another target for HAT is $N$-myristoyltransferase (NMT) that we have pursued at the Drug Discovery Unit (DDU) at the University of Dundee (Frearson et al. 2010; Brand et al. 2012).

Current methods for target-based drug discovery usually involve screening diverse or focused libraries against the molecular target. The hits are then characterized and optimized through rounds of design, synthesis and testing against protein and cell. The testing usually includes assays for potency, selectivity and pharmacokinetic properties. In terms of target validation, it is important to prove that the compounds are acting on-target, and that it is inhibition (or modulation) of the target that is causing the death of the parasite. The compounds are then assayed in animal models of infection. It is only at this stage that it becomes clear if the proposed drug target has a reasonable degree of validation. In other words, a very considerable amount of time and resource will be consumed before there is reasonable evidence that the target chosen is a valid drug target. Therefore it is important to choose drug targets very 
Table 2. Criteria for molecular targets developed at the DDU (Frearson et al. 2007; Wyatt et al. 2011)

\begin{tabular}{|c|c|c|c|}
\hline & Green & Amber & Red \\
\hline Essentiality & $\begin{array}{l}\text { Genetic and chemical validation } \\
\text { that the target is essential for } \\
\text { survival of the organism }\end{array}$ & $\begin{array}{l}\text { Genetic or chemical validation that } \\
\text { the target is essential for survival } \\
\text { of the organism }\end{array}$ & $\begin{array}{l}\text { No or weak genetic or chemical } \\
\text { validation that the target is } \\
\text { essential for survival of the } \\
\text { organism }\end{array}$ \\
\hline Druggability & $\begin{array}{l}\text { Drug-like, small molecule } \\
\text { inhibitors are known and there } \\
\text { is a druggable active site (clinical } \\
\text { activity within the target family) }\end{array}$ & $\begin{array}{l}\text { Drug-like, small molecule } \\
\text { inhibitors are known or the active } \\
\text { site is potentially druggable }\end{array}$ & $\begin{array}{l}\text { No drug-like, small molecule } \\
\text { inhibitors are known and the } \\
\text { active site is not druggable }\end{array}$ \\
\hline Assayability & $\begin{array}{l}\text { Robust assay in plate format } \\
\text { amenable to high-throughput } \\
\text { screening developed and active } \\
\text { protein supply assured within } \\
\text { appropriate time-lines }\end{array}$ & $\begin{array}{l}\text { In vitro assay exists, development } \\
\text { into robust, plate format feasible, } \\
\text { but not yet achieved }\end{array}$ & $\begin{array}{l}\text { No in vitro assay developed and/ } \\
\text { or significant problems with } \\
\text { protein supply }\end{array}$ \\
\hline $\begin{array}{l}\text { Resistance } \\
\text { potential }\end{array}$ & $\begin{array}{l}\text { Target has no known isoforms } \\
\text { within the same species and is } \\
\text { not subject to escape from } \\
\text { inhibition. }\end{array}$ & $\begin{array}{l}\text { Target has isoforms within same } \\
\text { species } \text { or may be subject to } \\
\text { escape from inhibition. }\end{array}$ & $\begin{array}{l}\text { Target has multiple gene copies } \\
\text { or isoforms within same species } \\
\text { and is subject to escape from } \\
\text { inhibition. }\end{array}$ \\
\hline $\begin{array}{l}\text { Toxicity } \\
\text { potential }\end{array}$ & $\begin{array}{l}\text { No human homologue of the } \\
\text { target present, or the human } \\
\text { homologue is known to be non- } \\
\text { essential and inhibition of this } \\
\text { shows no effect on the human } \\
\text { host }\end{array}$ & $\begin{array}{l}\text { Human homologue of the target is } \\
\text { present, but evidence (structural } \\
\text { or chemical) that selective } \\
\text { inhibition is possible }\end{array}$ & $\begin{array}{l}\text { Human homologue of the target } \\
\text { is present and little or no } \\
\text { evidence (structural or } \\
\text { chemical) that selective } \\
\text { inhibition is possible }\end{array}$ \\
\hline $\begin{array}{l}\text { Structural } \\
\text { information }\end{array}$ & $\begin{array}{l}\text { Ligand-bound structure of target } \\
\text { or ligand in closely related } \\
\text { homologue available at high } \\
\text { resolution }(<2 \cdot 3 \AA)\end{array}$ & $\begin{array}{l}\text { Structure without ligand available } \\
\text { and/or poor resolution }(>2 \cdot 3 \AA \text { ) } \\
\text { or opportunity to build a good } \\
\text { homology model (high sequence } \\
\text { homology to homologue) }\end{array}$ & $\begin{array}{l}\text { No structure of target or closely } \\
\text { related homologue }\end{array}$ \\
\hline
\end{tabular}

carefully at the outset of a drug discovery programme.

\section{TRAFFIC LIGHT SYSTEM}

At the DDU at the University of Dundee, we have carried out target-based drug discovery programmes against HAT. We use 6 criteria to help us select molecular targets to enter our drug discovery pipeline. The criteria are: essentiality, druggability, assayability, resistance potential, toxicity potential and structural information. To help compare between the different targets, we have established a 'traffic light' scoring system for the different criteria, as reported (Frearson et al. 2007; Wyatt et al. 2011). Essentially each criterion is given a green, amber or red score, according to a number of definitions, which are summarized in Table 2. This provides a rapid visual method to assess an individual target and to compare between different potential drug targets. The assignment of a 'red' score does not necessarily mean that this is a no-go situation; it could just indicate a lack of information. There are also clear cases for a no-go decision - for example, if it is shown that the target is not essential for survival of the parasite.

\section{Essentiality}

When designing a compound against a pathogen, it is important that the drug target is essential. This can be assessed both genetically and chemically. Genetic validation can be carried out in a number of ways. In many organisms this can be a complex process. In the case of $T$. brucei, there are more genetic tools available than with many other organisms; however, even in the case of this organism, genetic validation can still be problematic. In the case of $T$. brucei, it is possible to carry out RNAi to knock down the enzyme and see if there is a phenotypic response (Motyka and Englund, 2004; Ullu et al. 2004). A more rigorous method is to carry this out by knockout studies (Barrett et al. 1999; Beverley, 2003).

Whilst knockdown or knockout of a gene in cell culture can prove that a gene is essential to the viability of the parasite, it does not necessarily mean that it is a good drug target. There can be issues with druggability (see below). Other reasons that the genetic validation may not be sufficient include by-pass mechanisms that can occur in vivo. Furthermore, during knockout experiments the protein is removed. The protein may have a vital 'structural' role due to interactions with other proteins, rather than the reaction products being vital to the parasite. A further complication with genetic validation is the rate of kill. So for example, the enzyme trypanothione synthase is genetically essential for the viability of the parasite. However, genetic knockdown/knockout of the enzyme leads to a slow rate of killing of T. brucei, meaning an inhibitory drug concentration would have to be maintained for 
an extended period of time before any therapeutic effect is likely to be observed (Spinks et al. 2012).

\section{Druggability}

It is important that it is possible to obtain drug-like inhibitors of the enzyme active site that have the potential to fulfil the TPP. For example, if the TPP requires an oral drug, the binding pocket of the molecular target should have a good balance of polarity and hydrophobicity, and also present a reasonably-sized pocket. The pocket should not be too large, as this will probably require a large molecule to obtain good inhibition of the target. Similarly, for a pocket that is too small it may be difficult to obtain an inhibitor with sufficient selectivity and potency. This will mean that the inhibitor (which will have complementarity in both shape and charge distribution to the active site) is more likely to have the properties required for an oral drug (see below for more discussion). The best evidence for druggability is that there is clinical precedence for this target class. Whilst this level of information is not available for most targets, often there are literature reports of inhibitors or tool molecules that inhibit the target or close homologues of the target which guide target assessment. There are also computational methods to assess druggability, such as one produced at Dundee by Krasowski et al. (2011). Recently it has been reported that fragment screening is an effective way to assess druggability (Edfeldt et al. 2011).

\section{Assayability}

Developing robust assays, suitable for 384-well format screening can be a time-consuming challenge. There is now a large array of different screening platforms available and, for most enzymes, it is possible to derive an appropriate assay. A more significant problem is actually obtaining soluble, active proteins to carry out assays. Protein expression can be very challenging and we have identified a number of targets we were interested in investigating, but for which we were unable to obtain soluble, active proteins.

\section{Resistance potential}

Resistance is always going to be a problem with anti-infectives. There are many different ways by which resistance can occur; for example, single point mutations altering residues in the target, efflux pumps, over-expression of the target, gene amplification of the target, inactivation of the drug. Some of these are very difficult to predict but, in some cases, there are clear pathways available to resistance, such as isoforms within the same organism. In the case of many organisms it is possible to check this, through bioinformatic analysis of the genomes.

\section{Toxicity potential}

Toxicity can arise from a number of different causes. Toxicity can occur if there is a human homologue of the enzyme that is being targeted. It can be difficult to predict if compounds will inhibit both the pathogen enzyme and human homologue. Occasionally even if the pathogen and human enzymes have very similar enzyme structures, it can be possible to obtain highly selective inhibitors of one enzyme, for reasons that are not well understood. For example, in the DDU compounds were obtained that are very selective for the leishmania protein kinase CRK3, although it has a similar sequence in the active site to various human protein kinases (Cleghorn et al. 2011). Nevertheless, where there is a high level of similarity between the active sites of pathogen and human homologues, this should act as a significant risk factor when selecting potential drug targets in the absence of other information.

Toxicity can also arise from other unexpected interactions of compounds with the human host. Sometimes this can be deduced from the structure of the compound; hence many organizations remove potential toxic functionality (such as Michael acceptors) from their screening collections. Other toxicities are not easy to predict, and are often only picked up much later in the drug discovery process. Toxicity is one of the most significant reasons for attrition in the drug discovery process (Kola and Landis, 2004; Arrowsmith, 2011a,b).

\section{Structural information}

Whilst structural information on a protein (and ideally a protein-ligand complex) is very helpful for compound optimization for target-based programmes, it is not essential. Structural information is at its most powerful when it is possible to obtain co-crystal structures of the protein with inhibitors, as this guides the design process. It can be even more helpful if there is also a structure of the human homologue (where applicable) to guide selective inhibitor design. Therefore, although structural information is not critical to target-based drug discovery, it can be an extremely powerful tool to move projects along.

\section{PROPERTIES OF MOLECULES}

In terms of drug discovery, although it is important to have a good molecular target, it is equally important to develop the molecules with the correct properties to achieve the TPP. The TPP allows criteria to be set for compounds for the different stages of the drug discovery programme in terms of 
Table 3. Physicochemical properties of currently used drugs for kinetoplastid infections

\begin{tabular}{|c|c|c|c|c|c|c|}
\hline Compound & MW & $\operatorname{clog} \mathrm{P}^{\mathrm{a}}$ & $\mathrm{HBD}^{\mathrm{b}}$ & $\mathrm{HBA}^{\mathrm{b}}$ & PSA & RO5 \\
\hline Suramin & 1297 & $2 \cdot 2$ & 12 & 23 & 468 & $\mathrm{~N}$ \\
\hline Pentamidine & 340 & $2 \cdot 8$ & 6 & 4 & 118 & $\mathrm{~N}$ \\
\hline Melarsoprol & 398 & $1 \cdot 7$ & 6 & 4 & 123 & $\mathrm{~N}$ \\
\hline Eflornithine & 182 & $-3 \cdot 7$ & 5 & 4 & 89 & $\mathrm{Y}$ \\
\hline Nifurtimox & 273 & $-0 \cdot 2$ & 0 & 7 & 109 & $\mathrm{Y}$ \\
\hline Benznidazole & 260 & $0 \cdot 7$ & 1 & 4 & 93 & $\mathrm{Y}$ \\
\hline Amphotericin B & 924 & $-1 \cdot 2$ & 13 & 18 & 320 & $\mathrm{~N}$ \\
\hline Miltefosine & 408 & $6 \cdot 0$ & 0 & 4 & 56 & $\mathrm{~N}$ \\
\hline Paramomycin & 616 & $-3 \cdot 0$ & 18 & 20 & 347 & $\mathrm{~N}$ \\
\hline Stibogluconate ${ }^{c}$ & 680 & $-3 \cdot 5$ & 8 & 17 & 276 & $\mathrm{~N}$ \\
\hline Meglumine antimoniate ${ }^{\mathrm{c}}$ & 366 & & 7 & 9 & & $\mathrm{~N}$ \\
\hline
\end{tabular}

a $\operatorname{cog} P$ was calculated using StarDrop ${ }^{\text {TM }}$.

b HDB and HBA are given as defined by Lipinski (Lipinski et al. 2001).

c The precise structures of stibogluconate and meglumine antimoniate are not known.

potency, selectivity, pharmacokinetics and safety pharmacology. Given that during the discovery of a clinical candidate, the molecular weight and lipophilicity are likely to increase (Nadin et al. 2012), this should be taken into account when choosing the starting chemical library - compounds must be amenable to increases both in lipophilicity and molecular weight during optimization without compromising developability.

The TPPs for the kinetoplastid diseases generally require oral drugs. Lipinski defined his famous 'rule of 5 as a guide as to whether a molecule is in the correct chemical space to be an orally bioavailable compound (Lipinski et al. 1997). In his rules, compounds should have a molecular weight of less than $500, \operatorname{cog} \mathrm{P}<5$, less than 5 hydrogen bond donors and less than 10 hydrogen bond acceptors (Lipinski et al. 1997). Current thinking suggests that we should be even more stringent about the physicochemical properties of molecules. Analysis of drug molecules indicates for oral drugs, the average molecular weight is 333 and the average $\operatorname{cog} \mathrm{P}$ is 2.5 (Gleeson et al. 2011). $\log P$ in particular appears to be correlated to a number of developability issues, including toxicity, metabolic instability and insolubility (Leeson and Springthorpe, 2007; Hughes et al. 2008; Hann, 2011). Recent publications suggest an ideal $\operatorname{clog} P$ value lies in the range of $1-3$. In addition to $\operatorname{cog} P$ and MW, analysis indicates that other criteria are important in prospective drug candidates. (1) The 3-dimensionality is important in drug-molecules. Thus the proportion of $\mathrm{sp}^{3}$ carbon atoms in a drug is 0.47 (Lovering et al. 2009). Analysis indicates that in early drug discovery, the average proportion of $\mathrm{sp}^{3}$ carbon atoms is 0.36 and this gradually rises along the drug discovery pathway. The 3-dimensionality helps properties of molecules such as solubility by decreasing planarity and gives access to more chemical space. (2) The number of carbocyclic aromatic rings impacts negatively on the developability of molecules (Ritchie and MacDonald, 2009; Ritchie et al. 2011).
The number of carbocyclic aromatic rings is correlated with lower solubility, higher $\log \mathrm{D}$, higher plasma protein binding, hERG inhibition and inhibition of some major cytochrome P450s (3A4, 2C9, 2C19). (3) For compounds required to reach the CNS, there are additional criteria. Wager et al. at Pfizer have carried out a thorough analysis of properties of compounds that have CNS penetration (Wager et al. 2010a,b). This suggested a number of 'optimum' values for a number of factors - for example: $\operatorname{cog} \mathrm{P}=2 \cdot 8 ; \mathrm{MW}=305$; Polar surface area $(\mathrm{PSA})=45 ; \mathrm{HBD}=1 ; \mathrm{pKa}=8 \cdot 4$.

In addition to the physicochemical properties of molecules, many research laboratories filter out functional groups known to be chemically reactive or toxic (Brenk et al. 2008). In some cases this is a clear-cut decision. For example, acyl chlorides are too unstable to be developed. In other cases, the decisions about which groups to include and which to exclude are less clear. Therefore, excluding certain functional groups is a careful balancing act; excluding functional groups can make the compounds 'cleaner', but reduces the chemotypes covered. In some cases this becomes a judgement call, balancing the risks of certain chemical functionality against the risks of restricting the chemical space covered in a library. For example, nitro groups may be excluded due to potential genotoxicity concerns, although some drugs have aromatic nitro groups. It is important to understand the risk inherent in certain types of functional groups and to address this risk as early as possible in the discovery process, if it is decided to include these.

PROPERTIES OF CURRENT DRUGS USED FOR TREATMENT OF KINETOPLASTID INFECTIONS

Interestingly, if the current drugs used for the treatment of kinetoplastid diseases are analysed, it is clear that not many of them are ideal from a physicochemical perspective, given that the current 
<smiles>Cc1ccc(C(=O)Nc2ccc(S(=O)(=O)O)c3cc(S(=O)(=O)O)cc(S(=O)(=O)O)c23)cc1NC(=O)c1cccc(NC(=O)Nc2cccc(C(=O)Nc3cc(S(=O)(=O)O)ccc3C)c2)c1</smiles>

suranim<smiles>N=C(N)c1ccc(OCCCCCOc2ccc(C(=N)N)cc2)cc1</smiles>

pentamidine<smiles>Nc1nc(N)nc(Nc2ccc([As]3SCC(CO)S3)cc2)n1</smiles>

melarsoprol<smiles>NCCCC(N)(C(=O)O)C(F)F</smiles>

eflornithine<smiles>O=[N+]([O-])c1ccc(/C=N/N2CCS(=O)(=O)CC2)o1</smiles>
nifurtimox<smiles>O=C(Cn1ccnc1[N+](=O)[O-])NCc1ccccc1</smiles>

benznidazole

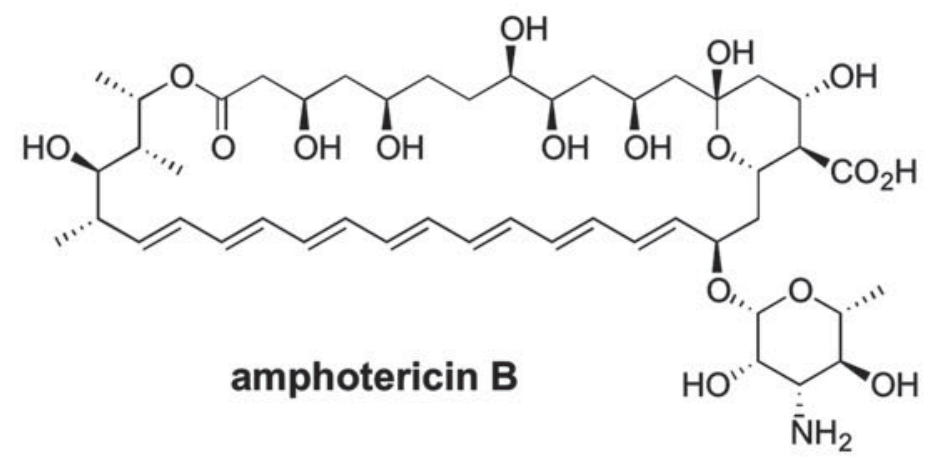<smiles>C[N+](C)(C)CCOP(=O)([O-])O[13CH3]</smiles>

miltefosine<smiles>NC[C@H]1O[C@H](O[C@H]2[C@H](O)[C@H](O[C@@H]3[C@@H](O)[C@H](N)C[C@H](N)[C@H]3O[C@@H]3O[C@H](CO)[C@@H](O)[C@H](O)[C@H]3N)O[C@@H]2CO)[C@H](N)[C@@H](O)[C@@H]1O</smiles>

paromomycin<smiles>O=C(O)[C@H]1O[Sb](=O)(O[Sb]2(=O)O[C@H](C(=O)O)[C@@H](O)[C@@H]([C@H](O)CO)O2)O[C@@H]([C@H](O)CO)[C@@H]1O</smiles>

sodium stibogluoncate<smiles>CNC[C@H](O)[C@@H](O)[C@H](O)[C@H](O)CO</smiles>

$\mathrm{O}_{\text {S. }}^{\mathrm{Sb}} \mathrm{O}^{-\mathrm{OH}}$

\section{meglumine antimoniate}

Fig. 1. Current drugs used for the treatment of kinetoplastid infections. 


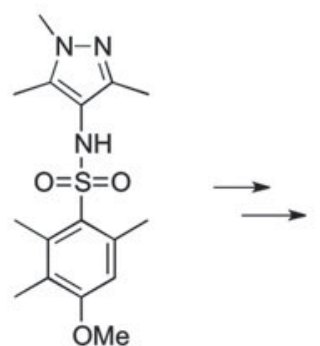

TbNMT, $I_{50}=1.9 \mu \mathrm{M}$ T.brucei, $\mathrm{EC}_{50}=21 \mu \mathrm{M}$

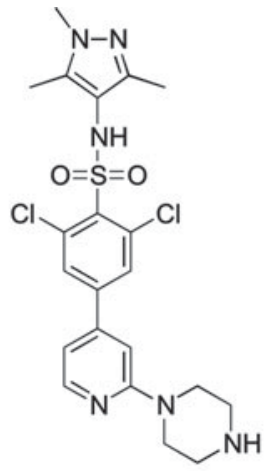

DDD85646

TbNMT, $\mathrm{IC}_{50}=0.002 \mu \mathrm{M}$

T.brucei, $\mathrm{EC}_{50}=0.002 \mu \mathrm{M}$
Fig. 2. Compounds active against T. brucei NMT.

TPPs for the kinetoplastid infections require oral drugs. Indeed most of the drugs are not orally bioavailable and require parenteral administration, as would be predicted by their physicochemical properties (Table 3 and Fig. 1). The only orally bioavailable drugs are nifurtimox, benznidazole and miltefosine. The former two are compliant with Lipinski's rules and whilst miltefosine has a $\log \mathrm{P}$ value of $>5$, miltefosine is zwitterionic and the $\operatorname{cog} \mathrm{D}$ value is 1.5 which is well within the Lipinski criteria. Eflornithine theoretically fulfils Lipinski's rules; however the compound is so hydrophilic $(\operatorname{cog} \mathrm{P}=-3 \cdot 7)$ that it is very unlikely to traverse membranes well by passive diffusion and is actually given by intravenous infusion.

Interestingly melarsoprol, nifurtimox and eflornithine are used for the treatment of stage $2 \mathrm{HAT}$, suggesting that the compounds are blood-brain barrier penetrants. Melarsoprol and nifurtimox are not predicted to be blood-brain barrier penetrants based on normal criteria as their polar surface areas are too high (Kelder et al. 1999). Eflornithine has a marginal level of PSA, but the negative $\operatorname{cog} \mathrm{P}$ and zwitterionic nature of the molecule suggest that it is not likely to be passively permeable. The uptake of these molecules is likely to be due to transportermediated uptake, which is very difficult to predict or plan for.

Whilst clearly there are compounds that are suitable as drug candidates that do not meet criteria such as Lipinski's rules, these mark the exception rather than the rule and the exceptions are difficult to predict as they involve factors such as transportermediated uptake. Therefore the physicochemical properties of molecules should be taken into account during the design process.

\section{N-MYRISTOYLTRANSFERASE (NMT)}

By way of example, in the DDU (University of Dundee), in collaboration with others, we have provided very strong validation of NMT as a drug target for HAT (Frearson et al. 2010; Brand et al. 2012). I will briefly summarize its validation process below.

NMT is an enzyme found in all eukaryotic cells; its function is co-translational modification of a number of proteins, by $N$-myristoylation of their $N$-terminal glycine atoms. NMT has been investigated as a potential target for fungal diseases by a number of companies; but, despite discovery of some very potent inhibitors, none of these have been progressed to market.

Within T. brucei, NMT has been genetically validated initially by RNAi experiments by Price et al. (2003), and then kinetically characterized by Panethymitaki et al. (2006) in York. We set about validation of NMT as a target in T. brucei. It was then established that when NMT is knocked-down by RNAi, the parasites are unable to establish an infection in mice, adding further genetic validation (Price et al. 2010). To obtain chemical validation, at the DDU, we profiled a number of reported inhibitors of fungal NMT against $T$. brucei NMT (Brand et al. 2012); but none of these showed significant inhibition of the $T$. brucei enzyme. We therefore carried out a high-throughput screen using a 62000 compound diversity library (Brenk et al. 2008) from the DDU. This led to identification of a series of pyrazole sulphonamides as hit molecules, with the most potent compound having an $\mathrm{IC}_{50}$ value of $1.9 \mu \mathrm{M}$ (Fig. 2). These were optimized to a potent inhibitor, DDD85646 with an $\mathrm{IC}_{50}$ value of $0.002 \mu \mathrm{M}$ against $T$. brucei NMT and $\mathrm{EC}_{50}$ value of $0.002 \mu \mathrm{M}$ against the parasite. We were then able to show that the compounds were active in rodent models of infection, both for T. b. brucei (curative at $12 \cdot 5 \mathrm{mg} / \mathrm{kg}$ po bid for 4 days) and $T$. $b$. rhodesiense (curative at $50 \mathrm{mg} / \mathrm{kg}$ po bid for 4 days).

In order to validate that these compounds were acting against NMT, a number of experiments were undertaken. These have been reported previously (Frearson et al. 2010), but are summarized here to show how they are important in validation of the target. (1) It was possible to obtain a co-crystal structure of the inhibitor DDD85646 with the $T$. brucei NMT homologue, Leishmania major NMT. This shows the inhibitor bound in the enzyme active site, occupying the peptide binding pocket. This is evidence that the compound can bind to the enzyme and that it binds in the substrate binding pocket. (2) We looked at a large number of inhibitors of $T$. brucei NMT and compared them to inhibition of parasite growth. There was a very good correlation between inhibition of the enzyme and inhibition of parasite growth, which is a good indication that inhibition of $T b$ NMT is responsible for the death of the parasites. (3) The gene encoding for NMT was over-expressed within the parasite $T$. bruce $i$ by about 5 -fold. This gave rise to an 8 -fold change in potency 
from $2 \cdot 1$ to $17 \mathrm{~nm}$. This indicates that the compounds are inhibiting NMT and that cell death is due to inhibition of NMT. (4) A further experiment was to incubate the parasites with radio-labelled myristic acid. This is incorporated into proteins through myristoylation, which could be checked by SDSPAGE. When the experiment was repeated in the presence of DDD85646, myristoylation is prevented and no radio-labelled proteins could be detected. This is good evidence that in cells, NMT inhibitors prevent myristoylation of proteins.

Therefore, through a suite of experiments, we have obtained good evidence that NMT is a valid drug target for HAT (Frearson et al. 2010). The target has been genetically validated through RNAi both in cells and in a mouse model of infection. We have demonstrated that our compounds inhibit NMT through binding to the peptide binding pocket of the enzyme. Inhibition of NMT prevents myristoylation of proteins in cells and leads to cell death of $T$. brucei. When dosed to mice orally, at sufficient levels to give unbound blood levels at $\mathrm{EC}_{99}$, these NMT inhibitors cure animal models of HAT.

In terms of physicochemical properties, these compounds are appropriate for oral bioavailability: i.e. $\mathrm{MW}=495 ; \quad \operatorname{cog} \mathrm{P}=3 \cdot 1 ; \quad \mathrm{HBD}=2 ; \quad \mathrm{HBA}=5$. However, DDD85646 does not have the correct physicochemical properties for CNS penetration, and indeed it is not active in a CNS model of infection. Interestingly when we started this project, there was a TPP for oral stage 1 compounds for HAT but during the work on this project, the priority was changed to requiring a TPP activity in the CNS stage 2 of infection. This demonstrates how TPPs can alter and the effect that they can have on the types of molecule that are required for the indication.

\section{CONCLUSION}

Target-based drug discovery is possible for HAT but careful selection of the molecular target must be made. Often there is insufficient information available to be certain of how valid selected molecular targets are at the beginning of a drug discovery project. It is therefore important that the correct biological experiments are carried out and tool molecules prepared to validate the molecular targets early in the project. These include genetic validation experiments and mode of action experiments with tool molecules to demonstrate that the tool molecules are acting on target and it is through inhibition of the target that they exert their antiparasitic activity. Thought must also be put into selection of compounds for screening and the compounds that are developed, to make sure that they have the correct physicochemical and pharmacokinetic properties.

\section{ACKNOWLEDGEMENTS}

I would like to acknowledge members of the Drug Discovery Unit at the University of Dundee (UK) for contributions to this HAT project and discussions around target validation and compound selection.

\section{FINANCIAL SUPPORT}

The NMT project in the Drug Discovery Unit was funded by the Wellcome Trust (WT077705 and WT083481).

\section{REFERENCES}

Arrowsmith, J. (2011a). Phase III and submission failures: 2007-2010. Nature Reviews Drug Discovery 10, 87.

Arrowsmith, J. (2011b). Trial watch: phase II failures: 2008-2010. Nature Reviews Drug Discovery 10, 328-329.

Barrett, M. P. (1999). The fall and rise of sleeping sickness. Lancet 353, 1113-1114.

Barrett, M.P. (2006). The rise and fall of sleeping sickness. Lancet 367, 1377-1378.

Barrett, M. P. and Croft, S. L. (2012). Management of trypanosomiasis and leishmaniasis. British Medical Bulletin 104, 175-196.

Barrett, M.P., Mottram, J.C. and Coombs, G.H. (1999). Recent advances in identifying and validating drug targets in trypanosomes and leishmanias. Trends in Microbiology 7, 82-88.

Beverley, S. M. (2003). Protozomics: trypanosomatid parasite genetics comes of age. Nature Reviews Genetics 4, 11-19.

Brand, S., Cleghorn, L. A., McElroy, S.P., Robinson, D. A., Smith, V. C., Hallyburton, I., Harrison, J. R., Norcross, N. R. Spinks, D., Bayliss, T., Norval, S., Stojanovski, L., Torrie, L. S., Frearson, J. A., Brenk, R., Fairlamb, A.H., Ferguson, M. A., Read, K. D., Wyatt, P. G. and Gilbert, I. H. (2012). Discovery of a novel class of orally active trypanocidal $N$-myristoyltransferase inhibitors. Fournal of Medicinal Chemistry 55, 140-152.

Brenk, R., Schipani, A., James, D., Krasowski, A., Gilbert, I. H., Frearson, J. A. and Wyatt, P. G. (2008). Lessons learnt from assembling screening libraries for drug discovery for neglected diseases. ChemMedChem 3, 435-444.

Brun, R., Don, R., Jacobs, R. T., Wang, M. Z. and Barrett, M. P. (2011). Development of novel drugs for human African trypanosomiasis. Future Microbiology 6, 677-691.

Cleghorn, L. A. T., Woodland, A., Collie, I., Torrie, L., Norcross, N., Luksch, T., Mpamhanga, C., Walker, R. G., Mottram, J. C., Brenk, R., Frearson, J. A., Gilbert, I. H. and Wyatt, P. G. (2011). Identification of inhibitors of the Leishmania cdc-related protein kinase CRK3. ChemMedChem 6, 2214-2224

Eastman, R. T., Buckner, F.S., Yokoyama, K., Gelb, M. H. and Van Voorhis, W. C. (2006). Fighting parasitic disease by blocking protein farnesylation. Fournal of Lipid Research 47, 233-240.

Edfeldt, F. N., Folmer, R.H. and Breeze, A. L. (2011). Fragment screening to predict druggability (ligandability) and lead discovery success. Drug Discovery Today 16, 284-287.

Frearson, J. A., Brand, S., McElroy, S. P., Cleghorn, L. A. T., Smid, O., Stojanovski, L., Price, H.P., Guther, M. L.S., Torrie, L.S., Robinson, D.A., Hallyburton, I., Mpamhanga, C.P., Brannigan, J. A., Wilkinson, A. J., Hodgkinson, M., Hui, R., Qiu, W., Raimi, O. G., Van Aalten, D.M.F., Brenk, R., Gilbert, I. H., Read, K. D., Fairlamb, A.H., Ferguson, M. A. J., Smith, D.F. and Wyatt, P. G. (2010). $N$-myristoyltransferase inhibitors as new leads to treat sleeping sickness. Nature 464, 728-732

Frearson, J. A., Wyatt, P. G., Gilbert, I. H. and Fairlamb, A. H. (2007). Target assessment for antiparasitic drug discovery. Trends in Parasitology 23, 589-595

Gilbert, I. H., Leroy, D. and Frearson, J. A. (2011). Finding new hits in neglected disease projects: target or phenotypic based screening? Current Topics in Medicinal Chemistry 11, 1284-1291.

Gillespie, J. R., Yokoyama, K., Lu, K., Eastman, R. T., Bollinger, J. G., Van Voorhis, W. C., Gelb, M. H. and Buckner, F. S. (2007). C-terminal proteolysis of prenylated proteins in trypanosomatids and RNA interference of enzymes required for the post-translational processing pathway of farnesylated proteins. Molecular and Biochemical Parasitology 153, 115-124. Gleeson, M. P., Hersey, A., Montanari, D. and Overington, J. (2011). Probing the links between in vitro potency, ADMET and physicochemical parameters. Nature Reviews Drug Discovery 10, 197-208. 
Hann, M. M. (2011). Molecular obesity, potency and other addictions in drug discovery. MedChem Comm 2, 349-355.

Hughes, J. D., Blagg, J., Price, D. A., Bailey, S., Decrescenzo, G. A. Devraj, R. V., Ellsworth, E., Fobian, Y. M., Gibbs, M. E., Gilles, R. W., Greene, N., Huang, E., Krieger-Burke, T., Loesel, J., Wager, T., Whiteley, L. and Zhang, Y. (2008). Physiochemical drug properties associated with in vivo toxicological outcomes. Bioorganic and Medicinal Chemistry Letters 18, 4872-4875.

Jacobs, R. T., Nare, B. and Phillips, M. A. (2011). State of the art in African trypanosome drug discovery. Current Topics in Medicinal Chemistry 11, 1255-1274.

Kelder, J., Grootenhuis, P. D. J., Bayada, D. M., Delbressine, L. P. C. and Ploemen, J.P. (1999). Polar molecular surface as a dominating determinant for oral absorption and brain penetration of drugs. Pharmaceutical Research 16, 1514-1519.

Kola, I. and Landis, J. (2004). Can the pharmaceutical industry reduce attrition rates? Nature Reviews Drug Discovery 3, 711-715.

Krasowski, A., Muthas, D., Sarkar, A., Schmitt, S. and Brenk, R. (2011). DrugPred: a structure-based approach to predict protein druggability developed using an extensive nonredundant data set. Fournal of Chemical Information and Modeling 51, 2829-2842.

Leeson, P. D. and Springthorpe, B. (2007). The influence of drug-like concepts on decision-making in medicinal chemistry. Nature Reviews Drug Discovery 6, 881-890.

Lipinski, C. A., Lombardo, F., Dominy, B. W. and Feeney, P. J. (1997) Experimental and computational approaches to estimate solubility and permeability in drug discovery and development settings. Advanced Drug Delivery Reviews 23, 3-25.

Lipinski, C. A., Lombardo, F., Dominy, B. W. and Feeney, P. J. (2001). Experimental and computational approaches to estimate solubility and permeability in drug discovery and development settings. Advanced Drug Delivery Reviews 46, 3-26.

Lovering, F., Bikker, J. and Humblet, C. (2009). Escape from Flatland: increasing saturation as an approach to improving clinical success. Fournal of Medicinal Chemistry 52, 6752-6756.

Motyka, S. A. and Englund, P. T. (2004). RNA interference for analysis of gene function in trypanosomatids. Current Opinion in Microbiology $\mathbf{7}$, 362-368.

Nadin, A., Hattotuwagama, C. and Churcher, I. (2012). Lead-oriented synthesis: a new opportunity for synthetic chemistry. Angewandte ChemieInternational Edition 51, 1114-1122.

Panethymitaki, C., Bowyer, P. W., Price, H. P., Leatherbarrow, R. J., Brown, K. A. and Smith, D. F. (2006). Characterization and selective inhibition of myristoyl-CoA: protein $N$-myristoyltransferase from Trypanosoma brucei and Leishmania major. Biochemical fournal 396, 277-285.

Price, H. P., Menon, M. R., Panethymitaki, C., Goulding, D., McKean, P. G. and Smith, D. F. (2003). Myristoyl-CoA:protein Nmyristoyltransferase, an essential enzyme and potential drug target in kinetoplastid parasites. Fournal of Biological Chemistry 278, 7206-7214.

Price, H.P., Guther, M. L.S., Ferguson, M. A. J. and Smith, D.F. (2010). Myristoyl-CoA:protein N-myristoyltransferase depletion in trypanosomes causes avirulence and endocytic defects. Molecular and Biochemical Parasitology 169, 55-58.

Ritchie, T. J. and MacDonald, S. J. F. (2009). The impact of aromatic ring count on compound developability - are too many aromatic rings a liability in drug design? Drug Discovery Today 14, 1011-1020.

Ritchie, T. J., MacDonald, S. J.F., Young, R. J. and Pickett, S. D. (2011). The impact of aromatic ring count on compound developability: further insights by examiing carbo- and hetero-aromatic and -aliphatic ring types. Drug Discovery Today 16, 164-171.

Spinks, D., Torrie, L. S., Thompson, S., Harrison, J. R., Frearson, J. A. Read, K. D., Fairlamb, A. H., Wyatt, P. G. and Gilbert, I. H. (2012) Design, synthesis and biological evaluation of Trypanosoma brucei trypanothione synthetase inhibitors. ChemMedChem 7, 95-106.

Ullu, E., Tschudi, C. and Chakraborty, T. (2004). RNA interference in protozoan parasites. Cellular Microbiology 6, 509-519.

Velez, N., Brautigam, C. A. and Phillips, M. A. (2013). Trypanosoma brucei S-Adenosylmethionine decarboxylase $\mathrm{N}$ terminus is essential for allosteric activation by the regulatory subunit prozyme. Fournal of Biological Chemistry 288, 5232-5240

Wager, T. T., Chandrasekaran, R.Y., Hou, X., Troutman, M.D., Verhoest, P. R., Villalobos, A. and Will, Y. (2010a). Defining desirable central nervous system drug space through the alignment of molecular properties, in vitro ADME, and safety attributes. ACS Chemical Neuroscience 1, 420-434.

Wager, T. T., Hou, X., Verhoest, P.R. and Villalobos, A. (2010b) Moving beyond rules: the development of a central nervous system multiparameter optimization (CNS MPO) approach to enable alignment of druglike properties. ACS Chemical Neuroscience 1, 435-449.

Wilkinson, S. R. and Kelly, J. M. (2009). Trypanocidal drugs: mechanisms, resistance and new targets. Expert Reviews in Molecular Medicine 11, e31.

Wyatt, P. G., Gilbert, I. H., Read, K. D. and Fairlamb, A. H. (2011). Target validation: linking target and chemical properties to desired product profile. Current Topics in Medicinal Chemistry 11, 1275-1283. 